\title{
Sexual and Reproductive Health Rights (SRHR) of Women in Rwanda: Challenges and Prospects
}

\author{
Frank Asiimwe* \\ UTAMU Resource Centre, Uganda

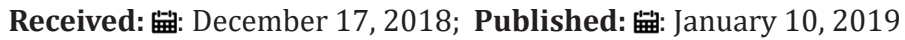 \\ *Corresponding author: Frank Asiimwe, UTAMU Resource Centre, Uganda
}

\begin{abstract}
This paper highlights the shortfalls in the current model and practices being used to provide Sexual and reproductive (SRH) services to women and girls in Rwanda and suggests the promotion of the rights approach in order to enhance the contribution of SRH services on the wellbeing of this group. This paper emphasizes the development of appropriate psychological, social-cultural and physical resources in both women and girls that will enable them to practice their rights to access available SRH services. The current SRH programs and practices do not empower women and girls to navigate their way to and negotiate for what they need for their well-being as individuals, and collectively within communities. The prevailing religious beliefs and myths about family planning have disempowered Women and girls to develop attitudes, values and skills to utilize available SRH services. Informal ways such as, Faith-based organizations, family and school SRH training activities and use of SRH materials like young talk magazines in schools and communities can reach all and create capacity among women and girls in terms of knowledge of SRH rights, and effective engagement skills for utilizing these services more fully.
\end{abstract}

Keywords: Sexual and Reproductive Health; Rights Approach; Effective Attitudes; Values and Skills Development

Abbreviations: SRH: Sexuality and Reproductive Health; RDHS: Rwanda Demographic Household Survey; STIs: Sexually Transmitted Infections

\section{Introduction}

\section{Status of Sexual and Reproductive Health among Women and Girls in Rwanda}

Sexuality and reproductive health (SRH) challenges is among the key problems affecting the wellbeing of girls and women in developing countries [1]. In most lands with limited resources, women and girls are unable to access the needed Sexual and Reproductive Health services. In Rwanda, Sexual and Reproductive Health problems are on the increase, despite school and community based interventions that have sought to reduce them in this population. Currently, more than $25 \%$ of girls aged $15-19$ in Rwanda have their first sexual experience by the age of 15 and $15 \%$ of births occur to teenage mothers [2]. About $15 \%$ of births in Rwanda occur to mothers below 20 years of age and this mostly due to unwanted and unplanned pregnancies [4]. STIs are fairly common among women and girls in Rwanda. A recent study revealed that, nearly half of young women who have STIs in Rwanda do not seek treatment mostly because they do not know their rights, did not want other people to know, did not know where to go or thought it cost too much [5]. Niyongere C [6] blames this state of affairs to both girls and women, not having enough information about conception, pregnancy, as well as safe and reliable family planning methods.

\section{The Problem}

Rwanda uses a disease prevention model to promote SRH among women and girls. This approach is effective in lands where people are empowered and have the necessary knowledge, attitudes and skills to utilize SRH services. However, women and girls in Rwanda are significantly influenced by religious beliefs on the way they think, and the choices of life make [7] . Therefore, use of this model has created a gap in access and utilization of these services in this group. Also, this model leaves out the key players in Sexual and Reproductive Health among women and girls in Rwanda, the community, parents and the school. The model does not emphasize rights promotion activities such as SRH rights education, policies on SRH information, Education and Communication activities for example; counselling for the school children, sensitizing the community on the needs of women and empowering parents to bring up their children in a manner that will enable them deal with these SRH issues. Subsequently the unmet reproductive health 
needs of women and girls in Rwanda have negatively impacted on their access to important life development opportunities such as education, employment and community participation. Women and girls in Rwanda need interventions that establish promote and reinforce appropriate SRH rights, skills and values. Women and girls with appropriate SRH knowledge, skills and values, may not be influence by myths and negative beliefs. However, this requires support intervention of SRHR promotion in this group.

\section{Challenges Facing Sexual and Reproductive Health Interventions in Rwanda}

Girard F [5] such inability to utilize available SRH services is often blamed on stigma and myths on SRH issues. This is still a very big problem in communities in Rwanda. Religious and cultural beliefs play a very important role in the lives of most Rwandese. The majority of them are Catholics and the Catholic Church still discourages contraception. This implies that many catholic girls and women maintain negative attitude on SRH issues and subsequently do not get the needed information and skills to act wise. Stigma on sexual health matters is rife in most communities in Rwanda and many girls believe in myths and misinformation passed around by their peers. For women as well, being able to access family planning methods is also sometimes difficult due to gender norms that give men more decision making power in relationships. Therefore, most women and girls find it difficult to obtaining sexual reproductive health services without a third person being involved. Furthermore, most health centers lack girls and women friendly SRH services and mentorship programmes to reach and empower them [7].

Following their religious and cultural beliefs, many families in Rwanda take sexuality and reproductive health issues as being sensitivity and are usually quiet about them [9]. Nomugisha H [7] says that the voices of women and girls are not usually listened to ,to find out what they need. Instead, assumptions are made about their SRH needs, thus ignoring and sometimes dismiss them altogether. The majority of young women base their SRH decisions on inaccurate peer and media information, which has led them into problems that have adversely affected their future lives. In this scenario where many are not aware of their SRH rights they are not unable to seek for effective SRH services.

Nordton J [4] say that SRH challenges are normally high in societies where people lack empowerment and equality. Rwanda still has gender inequality issues that that have sustained poverty and exploitation of women and girls. This scenario is predisposing many women in Rwanda to risky SRH behavior. Adolescent girls in many areas in Rwanda, become involved in risky sexual activities with married men called "sugar daddies", boda-boda (bicycle operators) and taxi drivers, and other economically attractive men in exchange for small items their parents cannot afford to buy for them [7]. Adolescent boys have the same kind of relationships with older married women. Poverty and the exchange of sex for material things along with alcohol abuse underlie many of the adolescent sexual activities, including early marriage, prostitution, and rape which is reported to occur frequently and after which the victims suffer social stigmatization [8].
Data from the 2006 Rwanda Demographic Household Survey (RDHS) shows that women in Rwanda are generally less educated than men. Although the gender gap has narrowed in recent years, $19 \%$ of women aged 15-49 have never been to school, compared with only $5 \%$ of men in the same age group. This implies that adolescent girls are likely to be less empowered than boys to make appropriate SRH decisions. Socio-economic factors have also aggravated the problem of providing SRH services to women and girls in Rwanda. Community leaders and parents widely hold that mechanisms for managing girls' sexuality and behaviour in general within traditional value systems have broken down. Traditionally, issues related to sexuality and reproductive health in Rwanda was a responsibility of the aunties and uncles. These experienced adults provided SRH information to the young people as they grew up. However, due to the changes in societies and the fast growing western cultural influence, the responsibility has shifted, and the young people are left out to find out on their own. Parents and guardians, who would be the most effective means of providing girls with knowledge on SRH rights, skills and values, have left the responsibility to teachers and well-wishers including peers. This has rendered the young women and girls being at risk and making uninformed decisions that they later regret.

\section{Prospects on Effective Sexual And Reproductive Health Interventions for Women and Girls in Rwanda}

Using a rights-based approach in providing Sexual and Reproductive Health services to women and girls in Rwanda can be more effective in reducing SRH challenges they face. A rights-based to SRH means the right for everyone, regardless of any aspects of identity, to make informed choices regarding their own sexuality and reproduction [5]. This includes the right to make informed choices about whether or when they have children, the right to access the full range of affordable and informed family planning services, including safe abortion, the right to accurate information and services to prevent and treat sexually transmitted infections (STIs), and sexual health information and education [8]. The rights based approach in Rwanda can be beneficial in challenging negative beliefs, myths, assumptions and established ineffective ways of working on ASRH issues. This approach will effectively also tackle equality, freedom and power issues that lie at the root of factors that predispose women and girls to SRH problems. However, without empowering, girls with appropriate knowledge on their SRHR and skills, women emancipation milestones so far achieved in Rwanda may be thwarted. [5] say that young women and girls need interventions that establish, promote and reinforce appropriate SRH knowledge, skills, values and rights awareness. So we need to develop and strengthen existing sensitization programs on the benefits of women claiming their rights because some of them still have the mentality that contraception is harmful to their health.

Women should be given a friendly platform to access SRH services. These centers will have the right people helping them with the services and information they need. This will prevent or even end unwanted pregnancies and even fight against sexually transmitted diseases. Allowing women and girls' access to 
information about their sexual and reproductive health and rights, including modern contraception and safe abortion, would prevent unplanned pregnancies, STIs, and would save the lives of some of the poorest, most marginalized women and girls. Besides, human rights are enshrined in a set of internationally agreed legal and moral standards that can the effectiveness of SRH programs if infused into them. These universally agreed standards are largely absent in most conventional SRH programs in Rwanda. The international rights conventions hold people and institutions that are in power accountable to fulfil their responsibilities towards those with less power (Girls and women). It also supports rights holders - the (woman and girls) to demand their sexuality related rights. This they can only do if they have the necessary knowledge $\mathrm{SRH}$ rights and the skills to pursue these rights.

The school can be used as an important entry point to educate girls and young women about their human, sexual and reproductive health rights so as to enhance their ability to pursue these services. There is need to have formal in school and out of school training on SRHR. Having SRHR clubs right from primary schools can be very instrumental in peer education and counselling. They need to be strengthened by providing material and monetary facilitation to run in- school and community SRHR education. Hand books are very effective in SRHR education. Relevant handbooks in both Kinyarwanda and English should be written and distributed for both primary and secondary schools. Evaluation visits should be increased to at least three in a term to enable schools get adequate technical support and supervision. SRH educational videos can be made and supplied to schools with video players to enhance SRH education during club time. There is need to have SRHR messages on T- shirts to use then as an effective education material. The T-shirts should have a variety of SRH messages encouraging school, and community support for SRH services. SRH Posters should be made out of more durable material such as canvas, or multimedia. An SRHR magazine, having students' and pupils' challenges and practical responses to these could be started in all schools in Rwanda.

\section{References}

1. Ademola Olajide (2014) Women Deliver Invest in Family Planning and Reproductive Health.

2. Aggleton P, K Wood (2004) Promoting Young People's Sexual and Reproductive Health. Stigma, Discrimination and Human Rights. Safe Passages to Adulthood Southampton: p. 48.

3. Cook R, Dickens B, Fathalla, M (2003) Reproductive Health and Human Rights. Oxford University Press, Oxford.

4. Nordton J, Dawson C (2000) Life skills and HIV/AIDS education. A manual and resource guide for intermediate phase school teachers. Johannesburg: Heinemann

5. Girard F (2003) Do We Need Sexual Rights? Choices: Sexual and Reproductive Health and Rights in Europe: Perspectives on Sexual Rights as Human Rights.

6. Niyongere C (2016) Adolescent Girls Advocacy \& Leadership Initiative. Economic Empowerment Strategies for Adolescent Girls.

7. Nomugisha H (2017) Plan International. Economic Security Strategy 2010-2015: Promoting the Economic Rights of Children and Young People.

8. (2013) World Population Day Focuses on Adolescent Pregnancy. United Nations Population Fund Web site.

9. (2013) United Nations Population Fund. Motherhood in Childhood: facing the challenge of adolescent pregnancy.
ISSN: 2574-1241

DOI: $10.26717 / B J S T R .2019 .13 .002338$

Frank Asiimwe. Biomed J Sci \& Tech Res (c) (P) This work is licensed under Creative

Submission Link: https://biomedres.us/submit-manuscript.php

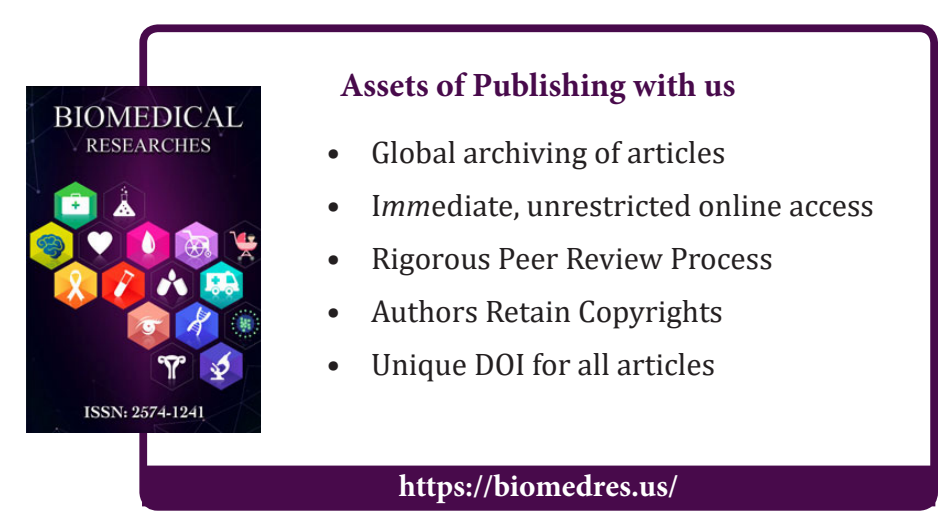

